\title{
Disturbed noradrenergic blood pressure control in normotensive members of hypertensive families
}

\author{
M G BIANCHETTI, P WEIDMANN, C BERETTA-PICCOLI, U RUPP, K BOEHRINGER, \\ L LINK, C FERRIER \\ From the Medizinische Poliklinik, University of Berne, Switzerland
}

SUMMARY The possible influence of a family history of hypertension on some variables of adrenergic blood pressure regulation was assessed. Blood pressure, heart rate, plasma renin activity, adrenaline and noradrenaline concentrations, and plasma or urinary electrolyte estimations did not differ significantly between two groups of normotensive subjects matched for age and sex with and without a family history of hypertension. Compared with subjects without a family history, however, an appreciably decreased pressor dose of infused noradrenaline, a distinct shift to the left in the relation between noradrenaline induced changes in mean arterial pressure and concomitant plasma noradrenaline concentrations, and an enhanced pressor response to given increases in plasma noradrenaline concentrations occurred in the group with a family history.

These findings suggest that an imbalance between cardiovascular noradrenaline responsiveness and circulating noradrenaline is a common familial disturbance which could possibly predispose to the development of essential hypertension.

The development of essential hypertension may be predisposed to by certain familial abnormalities in cardiovascular control mechanisms. Several isolated disturbances have been reported in normotensive offspring of hypertensive parents and include: $(a)$ an exaggerated sensitivity of the forearm vasculature to exogenous noradrenaline ${ }^{1}$ or of the renal vessels to psychological stimuli, ${ }^{2}(b)$ an increased responsiveness of blood pressure to mental stress ${ }^{3}$ or dietary potassium restriction, ${ }^{4}(c)$ high plasma catecholamine concentrations during stress, ${ }^{3}(d)$ a tendency to low plasma volume, ${ }^{5}$ and $(e)$ defects in the transmembranous cation transport of blood cells. ${ }^{67}$ Whether, and to what extent, these aberrations are hereditary components in the pathogenesis of essential hypertension is presently unclear. Moreover, exaggerated vascular or pressor responses to noradrenaline ${ }^{1}$ or stress $^{3}$ could either be a primary abnormality in end organ sensitivity or reflect altered activity of the sympathetic nervous system or other regulatory components or both.

A simultaneous analysis of both blood concentrations and cardiovascular effects of noradrenaline

Requests for reprints to Professor Peter Weidmann, Medizinische Poliklinik, Freiburgstrasse 6, CH-3010 Berne, Switzerland.

Accepted for publication 27 October 1983 might allow a more integrated assessment of noradrenergic blood pressure control in man. Since no such data have been reported we undertook the present study to determine the relation between cardiovascular noradrenaline pressor responsiveness and concomitant plasma noradrenaline concentrations in normotensive members of hypertensive families compared with that in age and sex matched normotensive members of normotensive families.

\section{Subjects and methods}

Twenty five healthy, non-obese, normotensive volunteers with a family history of essential hypertension (group 1) and a similar sex and age matched group without a history (group 2) were studied (Table 1).

\section{FAMILY HISTORY}

A family tree was constructed for each subject, and information on blood pressure obtained both by questioning the subjects and their families and direct from the family doctors and their medical records. In the group with a family history of hypertension (group 1) at least one or both parents or any existing siblings had essential hypertension; eighteen subjects had a parent, six both parents, and one a sibling and a parent with hypertension. In the group without a family 
Table 1 Clinical data and basal values (means $\pm S D$ ) of variables in normotensive subjects with (group 1) or without (group 2) a family history of essential hypertension

\begin{tabular}{|c|c|c|}
\hline & Group 1 & Group 2 \\
\hline & $(n=25)$ & $(n=25)$ \\
\hline $\begin{array}{l}\text { Sex }(M / F) \\
\text { Age (yrs) } \\
\text { Height }(\mathrm{cm}) \\
\text { Weight }(\mathrm{kg}) \\
\text { Heart rate }(\text { beats/min }) \\
\text { Blood pressure }(\mathrm{mm} \mathrm{Hg}) \\
\text { Urinary sodium }(\mathrm{mmol} / 24 \mathrm{~h}) \\
\text { Urinary potassium }(\mathrm{mmol} / 24 \mathrm{~h}) \\
\text { Plasma concentrations }\end{array}$ & $\begin{array}{l}14 / 11 \\
23 \cdot 4 \pm 3 \cdot 1 \\
175 \pm 9 \\
66 \pm 9 \\
62 \pm 10 \\
113 / 70 \pm 11 / 9 \\
174 \pm 61 \\
72 \pm 29\end{array}$ & $\begin{array}{l}14 / 11 \\
24 \cdot 1 \pm 3 \cdot 6 \\
174 \pm 8 \\
67 \pm 9 \\
62 \pm 11 \\
109 / 71 \pm 9 / 8 \\
168 \pm 90 \\
66 \pm 28\end{array}$ \\
\hline $\begin{array}{l}\text { Sodium }(\mathrm{mmol} / /) \\
\text { Potassium }(\mathrm{mmol} / \mathrm{l}) \\
\text { Creatinine }(\mu \mathrm{mol} / \mathrm{l}) \\
\text { Adrenaline }(\mathrm{nmol} / \mathrm{h}) \\
\text { Noradrenaline }(\mathrm{nmol} / \mathrm{l}) \\
\text { Plasma renin activity }(\mathrm{nmol} / \mathrm{h}) \\
\text { Pressor dose of infused noradrenaline }(\mathrm{nmol} / \mathrm{kg} / \mathrm{min})\end{array}$ & $\begin{array}{l}139 \pm 2 \\
4 \cdot 12 \pm 0.26 \\
84 \pm 9 \\
0.22 \pm 0.08 \\
1.31 \pm 0.72 \\
0.92 \pm 0.46 \\
0.49 \pm 0.17\end{array}$ & $\begin{array}{l}139 \pm 2 \\
4 \cdot 12 \pm 0.30 \\
86 \pm 10 \\
0.18 \pm 0.08 \\
1.42 \pm 0.81 \\
1.20 \pm 0.71 \\
0.84 \pm 0.45\end{array}$ \\
\hline
\end{tabular}

${ }^{\star} \mathrm{p}<0.001$ (group 1 vs group 2).

history (group 2) neither parent nor any existing siblings had known previous episodes of hypertension; they had a normal blood pressure recorded at least once in the year preceding the investigation, and there was no evidence of hypertension in the grandparents, although the latter information was incomplete in two subjects. Subjects with an uncertain family history of hypertension and women taking hormonal contraceptives were excluded from the study. Blood pressure readings were related to age and sex and hypertension defined according to Hamilton et al. ${ }^{8}$ Secondary forms of hypertension were excluded by the usual tests, 9 including blood concentrations of creatinine, sodium, and potassium as well as conventional urine examination in all and intravenous urography, renal angiography, or determination of aldosterone and catecholamine concentrations in a few hypertensive relatives.

\section{STUDY PROCEDURE}

All subjects were instructed to take a normal diet free of very salty food and without added salt at least five days before the study. ${ }^{1011}$ All were informed about the investigative nature of the study and gave their informed consent.

During the 24 hours before the study urine was collected for determining sodium and potassium excretion rates. On the morning after an overnight fast with the subjects resting supine an intravenous infusion of $5 \%$ dextrose in water $(0.1 \mathrm{ml} / \mathrm{min})$ was infused slowly during a 60 minute equilibration period. Basal blood pressure and heart rate were measured and blood samples collected through an indwelling intravenous cannula (positioned at least 30 to 60 minutes before on the opposite arm to the infusion) for determining basal plasma sodium, potas- sium, creatinine, noradrenaline, and adrenaline concentrations and plasma renin activity. These measurements were obtained between 8 am and $10 \mathrm{am}$. The dextrose infusion was then replaced by a solution of levarterenol bitartrate in 5\% dextrose (60-120 mmol noradrenaline base/l). Noradrenaline was infused at different rates, which were maintained over 20 minutes and increased stepwise. All subjects received at least three different dose rates of noradrenaline (mean $\pm S D, 0.13 \pm 0.03,0.26 \pm 0.08$, $0.63 \pm 0.14 \mathrm{nmol} / \mathrm{kg} / \mathrm{min}$ in group 2 and $0.12 \pm 0.01$, $0.24 \pm 0.02$, and $0.61 \pm 0.05$ in group 1 ). In 15 subjects in group 2 and in seven in group 1, a further infusion step with $1.20 \pm 0.11$ and $1.21 \pm 0.12 \mathrm{nmol} / \mathrm{kg} / \mathrm{min}$ respectively was necessary to increase mean arterial pressure by at least $20 \mathrm{~mm} \mathrm{Hg}$. Blood pressure and heart rate were measured every 60 seconds during the last 10 minutes of each infusion step, and blood samples were obtained at the end of each infusion step for determining plasma noradrenaline concentrations.

Blood pressure was measured with the automatic recorder Physiometrics SR 2 which was calibrated against a mercury manometer. Each value used for analysis was the mean of at least eight measurements. Mean arterial pressure was calculated as the sum of the diastolic and one third of pulse pressure. The relation between infused noradrenaline, noradrenaline blood concentrations, blood pressure, and heart rate was assessed by plotting curves for the relation between $(a)$ infused noradrenaline and concomitant changes in blood concentrations, $(b)$ noradrenaline dose rates and changes in mean arterial pressure, ${ }^{12}(c)$ noradrenaline induced changes in mean arterial pressure and plasma noradrenaline concentrations before and during infusion, and $(e)$ noradrenaline induced changes in mean arterial pressure and concomitant 
changes in heart rate. The pressor dose of infused noradrenaline was defined as the dose necessary to increase the mean arterial pressure by $20 \mathrm{~mm} \mathrm{Hg} .{ }^{13}$ Sodium and potassium concentrations were measured by a flame photometer, creatinine concentrations by an autoanalyser, renin activity by a radioimmunoassay, ${ }^{14}$ and plasma catecholamine concentrations by a radioenzymatic method, 15 as reported previously from this laboratory. 1012 Since natural logarithmic transformation ${ }^{16}$ rather than absolute values followed a Gaussian distribution the natural logarithmic transformation of renin activity, noradrenaline and adrenaline concentrations, changes in noradrenaline concentration, doses of infused noradrenaline, and pressor doses of noradrenaline was used for statistical analysis. ${ }^{1112}$ An unpaired (two tail) Student's $t$ test was used for comparing mean values between the two study group ${ }^{17}$ and regression analysis and analysis of covariance for comparing two regression coefficients. ${ }^{18}$ Significance was assumed when $p<0.05$. Results 1920 are expressed as means and standard deviations $( \pm S D)$ and for regressions as mean estimates and standard errors of estimate $( \pm S E E)$.

\section{Results}

Mean values for age, height, body weight, blood pressure, heart rate, plasma or urinary sodium and potassium concentrations, plasma creatinine concentration, renin activity, and noradrenaline or adrenaline concentrations did not differ significantly between the two groups (Table 1).

Noradrenaline infused at a dose of $600 \mathrm{pmol} / \mathrm{kg} / \mathrm{min}$ increased mean arterial pressure by $23.2 \pm 6.9( \pm$ SEE) $\mathrm{mm} \mathrm{Hg}$ in the subjects in group 1 and by $17 \cdot 1 \pm 7 \cdot 1$ $\mathrm{mm} \mathrm{Hg}$ in those in group $2(\mathbf{p}<0.01)$. Despite similar preinfusion plasma noradrenaline concentrations, the mean noradrenaline pressor dose was appreciably lower in group 1 than in group 2 (489 \pm 173 compared with $841 \pm 450 \mathrm{pmol} / \mathrm{kg} / \mathrm{min} ; \mathrm{p}<0.001$ ) (Table 1). The mean noradrenaline pressor dose was slightly lower in six subjects with two hypertensive parents than in 18 subjects with one hypertensive parent $(422 \pm 161$ and $511 \pm 176 \mathrm{pmol} / \mathrm{kg} / \mathrm{min}$ respectively).

The linear relation between noradrenaline induced changes in mean arterial pressure and plasma noradrenaline concentrations measured before and during noradrenaline infusion was significantly displaced to the left $(F=4.62 ; p<0.01)$ in group 1 compared with that in group 2 (Fig. 1). The estimated changes in mean arterial pressure for a plasma noradrenaline concentration of $20 \mathrm{nmol} / \mathrm{l}$ were about $50 \%$ greater in group 1 than in group 2 $(30.1 \pm 6.5( \pm S E E)$ compared with $19.8 \pm 6.2 \mathrm{~mm} \mathrm{Hg}$ respectively).

The relation between increases in plasma noradrenaline during infusion and corresponding changes

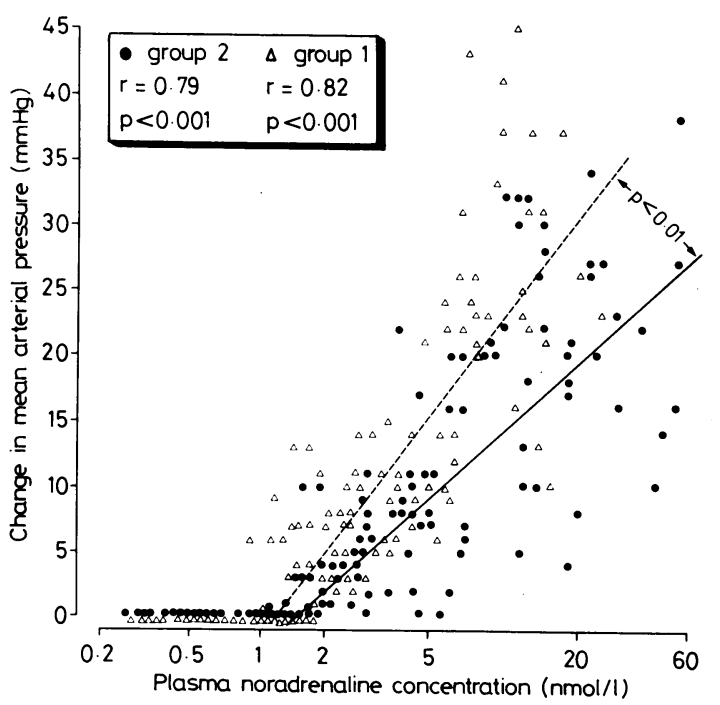

Fig. 1 Relation between plasma noradrenaline concentrations before and during noradrenaline infusion and associated changes in mean arterial pressure in normotensive subjects with (group 1) or without (group 2) a family history of hypertension. Linear regression equations are: group 2 (broken line), $y=-0.43+6.87$ In $x$; group 2 (solid line), $y=-0 \cdot 22+10 \cdot 11 \ln x$.

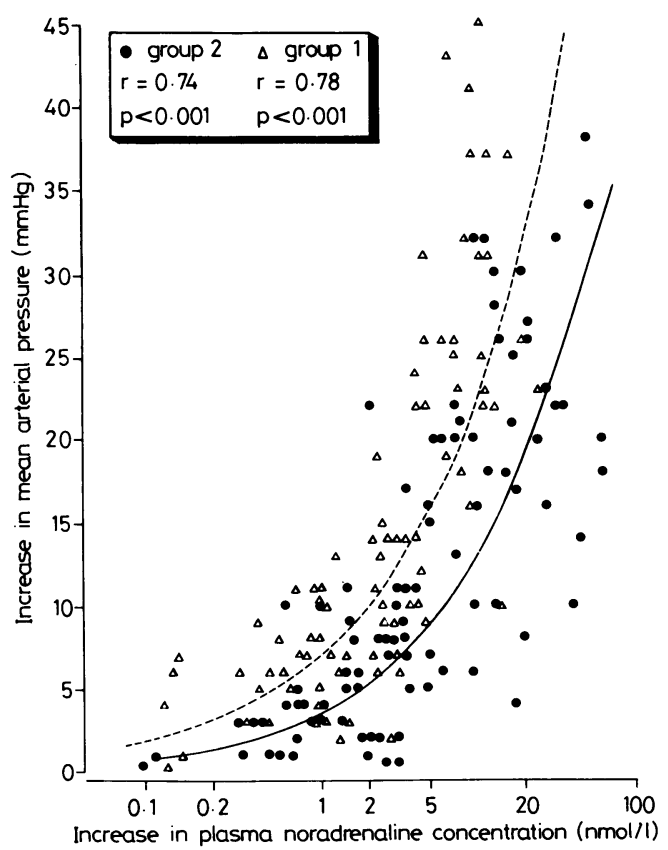

Fig. 2 Relation between increases in plasma noradrenaline concentrations and changes in mean arterial pressure in normotensive subjects with (group 1) or without (group 2) a family history of hypertension. Exponential regression equations are: group 2 (broken line), $y=3.45$ e 0.57 In $x$; group 1 (solid line), $y=6.90$ e $0.51 \ln x$. 


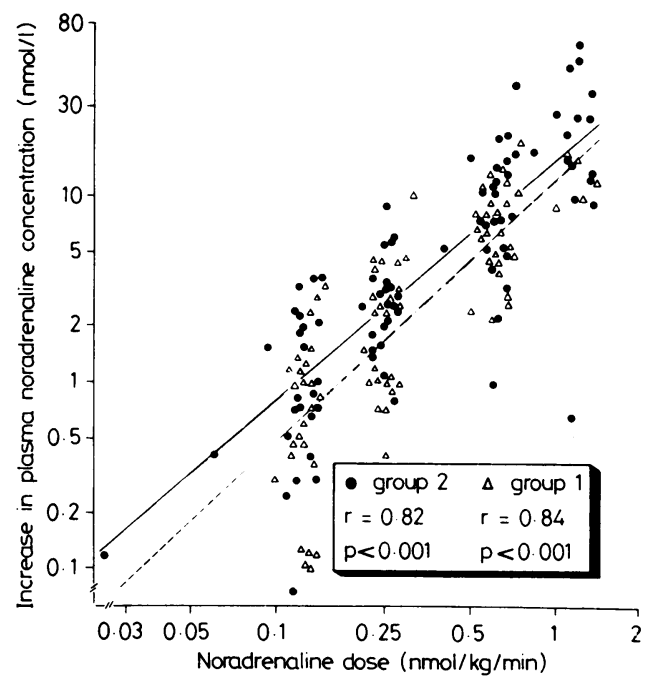

Fig. 3 Relation between noradrenaline infusion rate and increase in plasma noradrenaline concentrations in normotensive subjects with (group 1) or without (group 2) a family history of hypertension. Linear regression equations are: group 2 (broken line), In $y=2.83+1.53$ In $x ;$ group 1 (solid line), In $y=2 \cdot 71+1 \cdot 57 \ln x$.

in mean arterial pressure was exponential in both groups (Fig. 2). The two curves were largely comparable in their lower part. In the upper part the curves were parallel, but the curve in group 1 was distinctly displaced to the left. An increase in plasma noradrenaline concentration of $20 \mathrm{nmol} / 1$ was associated with an increase in mean arterial pressure of 19.1 \pm 6.5 $( \pm$ SEE) $\mathrm{mm} \mathrm{Hg}$ in group 2 and of $31.7 \pm 6.9$ in group $1(\mathrm{p}<0.01)$.

Changes in plasma noradrenaline concentration during infusion correlated linearly with corresponding noradrenaline infusion rates. This correlation did not differ between the two groups (Fig. 3). Mean increases in plasma noradrenaline concentration for a given rate of infusion did not differ significantly between the two groups, although they tended to be slightly greater in group 2 (Table 2 ).

Heart rate was decreased during the pressor response to noradrenaline infusion. Decreases in heart rate correlated linearly with increases in mean arterial pressure in group $2(\mathrm{r}=0.41 ; \mathrm{p}<0.025)$ and in group 1 $(\mathrm{r}=0.36 ; \mathrm{p}<0.05)$. Moreover, an increase in mean arterial pressure of $20 \mathrm{~mm} \mathrm{Hg}$ was associated with a similar heart rate response in the two groups $(-8.2 \pm 3.4( \pm \mathrm{SEE})$ (group 1) and $-8.4 \pm 3.7$ beats/ min (group 2).
Table 2 Mean $( \pm S D)$ increases in plasma noradrenaline concentrations (nmolll) in relation to stepwise increase in infusion rate of noradrenaline

\begin{tabular}{lll}
\hline Infusion rate & Group 1 & Group 2 \\
\hline Step 1 & $0.94 \pm 0.88$ & $1.49 \pm 1 \cdot 31$ \\
Step 2 & $2.58 \pm 2.09$ & $4.08 \pm 4.38$ \\
Step 3 & $13.41 \pm 11.33$ & $7.98 \pm 4.33$ \\
Step 4 & $26.61 \pm 19.67$ & $19.41 \pm 6.32$ \\
\hline
\end{tabular}

\section{Discussion}

In the present study an exaggerated mean cardiovascular pressor response to infused noradrenaline occurred in normotensive members of hypertensive families compared with that in age and sex matched members of normotensive families. On the other hand, there was no evidence of alteration in basal adrenergic tone since blood concentrations of noradrenaline and adrenaline and renin activity did not differ significantly between the two groups. The disturbance in subjects with a family history of essential hypertension was characterised by $(a)$ a significant $(\mathrm{p}<0.001)$ decrease in the noradrenaline pressor dose, (b) a significant $(\mathrm{p}<0.001)$ shift to the left in the relation between noradrenaline induced changes in mean arterial pressure and plasma noradrenaline concentrations measured before and during noradrenaline infusion, and $(c)$ a significantly $(\mathrm{p}<0.01)$ enhanced pressor response when plasma noradrenaline concentrations increased by $20 \mathrm{nmol} / \mathrm{l})$. In a previous report another response index-namely, the sensitivity of forearm blood flow to noradrenaline-was also increased in normotensive sons of hypertensive parents ${ }^{1}$; however, concomitant measurements of endogenous plasma noradrenaline concentrations were not available. The latter factor is important for interpretation, since noradrenaline pressor responsiveness correlated inversely with basal plasma noradrenaline concentrations in normotensive subjects ${ }^{11}{ }^{13}$ as well as in those with borderline ${ }^{12}$ or established essential hypertension. ${ }^{1113}$ In our normotensive subjects plasma concentrations of noradrenaline were normal and comparable with those previously observed in our and other studies. 101221 The association of exaggerated noradrenaline responsiveness with normal plasma noradrenaline concentrations in our normotensive subjects from hypertensive families is consistent with a disturbed relation between sympathetic nervous activity and cardiovascular reactivity to the sympathetic input.

Since the two study groups were selected on the basis of their family history of essential hypertension using complete medical data from their parents, siblings, and grandparents, familial clustering of hypertension could be reliably estimated. Our group of sub- 
jects with a family history was not homogeneous as subjects with one or two hypertensive parents were included. The latter have been reported to develop hypertension more often than the former. ${ }^{22}$ A study of a homogeneous group of subjects with two hypertensive first degree relatives would possibly reduce the overlap of individual noradrenaline responses with those observed in subjects from normotensive families. Thus mean noradrenaline pressor dose tended to be even lower in the six subjects with two hypertensive parents than in the 18 with only one hypertensive parent $(422$ vs $511 \mathrm{pmol} / \mathrm{kg} / \mathrm{min})$. Nevertheless, the tendency for exaggerated noradrenaline reactivity was clearly apparent and significant in the study group as a whole.

Familial factors include the effects of inheritance or environment or both. This study did not distinguish between genetic or environmental factors. Studies of adoptees ${ }^{23}$ and twins ${ }^{24}$ provide some evidence that a major factor is inherited.

Several mechanisms modify pressor responses. Exaggerated pressor responses could result from altered baroreflexes or excessive sodium intake or increased extracellular contents of sodium and fluid volume. ${ }^{2526}$ Since noradrenaline has a direct cardiac action an exact assessment of baroreflex responses could not be made during noradrenaline infusion. Nevertheless, the obvious similarity of changes in heart rate during infusion of noradrenaline in our normotensive subjects without and with a family history of hypertension suggests that the increased pressor response in the latter group was not due to decreased baroreflex sensitivity.

Dietary sodium and potassium intake, as judged by 24 hour urinary excretion rates, also did not differ between the two groups. Moreover, a tendency for low blood volume in normotensive members of hypertensive families ${ }^{5}$ would be expected to blunt rather than increase cardiovascular pressor responsiveness. Moreover, the exaggerated noradrenaline responses in the normotensive members of hypertensive families could not be explained by altered metabolism of circulating noradrenaline, since the relation between noradrenaline infusion rates and plasma noradrenaline concentrations was similar in both groups. Increased pressor responses may develop as a consequence of hypertension induced structural changes in the blood vessel walls, ${ }^{27}$ but the actual blood pressure was similar in the two groups, and none of the subjects had a known previous episode of hypertension. Hypertensive families may possibly carry an abnormality in the regulation of vascular smooth muscle cells. Whether defects in blood cell cation transport ${ }^{6}{ }^{7}$ reflect a more generalised disturbance also affecting cardiovascular muscle cells is presently unclear. Nevertheless, such a mechanism could attract enough calcium into cells to cause an increase in vascular tone. ${ }^{28}$ Another, but similarly speculative, mechanism may be a deviation from the physiological relation between certain vasoconstrictor and vasodilator prostaglandins. ${ }^{29}$

Essential hypertension is commonly associated with a disturbed relation between plasma noradrenaline concentrations and the cardiovascular responsiveness to noradrenaline. Previous studies in patients with established hypertension showed exaggerated depressor responses to sympathetic inhibition ${ }^{30}$ and an increased pressor responsiveness to noradrenaline ${ }^{11-13}$ despite normal ${ }^{11}$ or sometimes even high ${ }^{13}$ plasma noradrenaline concentrations. Patients with borderline hypertension had a similar disturbance. ${ }^{12}$ Our observations suggest that an imbalance between cardiovascular noradrenaline responsiveness and circulating noradrenaline is a common familial disturbance which often precedes and possibly predisposes to the development of essential hypertension.

We acknowledge the technical assistance of Mrs G Haueter, Mrs M C Wimpfheimer, Miss R Mosimann, and Miss B von Gunten. This work was supported by the Swiss National Science Foundation.

\section{References}

1 Doyle AE, Fraser JRE. Essential hypertension and inheritance of vascular reactivity. Lancet 1961; ii: 50911.

2 Hollenberg NK, Williams GH, Adams DF. Essential hypertension: abnormal renal vascular and endocrine responses to a mild psychological stimulus. Hypertension 1981; 3: 11-7.

3 Falkner B, Onesti G, Angelakos ET, Fernandes M, Langman C. Cardiovascular response to mental stress in normal adolescents with hypertensive parents. Hemodynamics and mental stress in adolescents. Hypertension 1979; 1: 23-30.

4 Parfrey PS, Condon K, Wright P, et al. Blood pressure and hormonal changes following alteration in dietary sodium and potassium in young men with and without a familial predisposition to hypertension. Lancet 1981; i: 113-7.

5 Ohlsson $\mathrm{O}$, Henningsen NC. Hemodynamic investigations on relatives of patients with essential hypertension. Acta Med Scand 1979; 205 (suppl 625): 7-12.

6 Garay RP, Meyer P. A new test showing abnormal net $\mathrm{Na}+$ and $\mathrm{K}+$ fluxes in erythrocytes of essential hypertensive patients. Lancet 1979; i: 349-53.

7 Dorst KG, Zidek W, Losse H, Zumkley H, Wollnik S, Vetter H. Intrazelluläres Natrium und Calcium als genetische Marker der essentiellen Hypertonie. Schweiz Med Wochenschr 1981; 111: 1964-6.

8 Hamilton M, Pickering GW, Roberts JAF, Sowry GSC. The aetiology of essential hypertension I. The arterial pressure in the general population. Clin Sci 1954; 13: 11-35. 
9 Weidmann P. Rationale Diagnostik bei Hypertonie. Ther Umsch 1981; 38 (suppl): 2-16.

10 Weidmann P, Beretta-Piccoli C, Ziegler WH, Keusch G, Gluck Z, Reubi FC. Age versus sodium for judging renin, aldosterone, and catecholamine levels: studies in normal subjects and patients with essential hypertension. Kidney Int 1978; 14: 619-28.

11 Weidmann P, Grimm M, Meier A, et al. Pathogenic and therapeutic significance of cardiovascular pressor reactivity as related to plasma catecholamines in borderline and established essential hypertension. Clin Exp Hypertens 1980; 2: 427-49.

12 Meier A, Weidmann P, Grimm M, et al. Pressor factors and cardiovascular pressor responsiveness in borderline hypertension. Hypertension 1981; 3: 367-72.

13 Philipp T, Distler A, Cordes U. Sympathetic nervous system and blood-pressure control in essential hypertension. Lancet 1978; ii: 959-63.

14 Sealey JE, Gerten-Banes J, Laragh JH. The renin system: variations in man measured by radioimmunoassay or bioassay. Kidney Int 1972; 1: 240-53.

15 Da Prada M, Zürcher G. Simultaneous radioenzymatic determination of plasma and tissue adrenaline, noradrenaline and dopamine within the femtomole range. Life Sci 1976; 19: 1161-74.

16 Gaddum JH. Lognormal distributions. Nature 1945; 156: 463-6.

17 O'Brien PC, Shampo MA. Statistics for clinicians: 6. Comparing two samples (the two-sample $t$-test). Mayo Clin Proc 1981; 56: 393-4.

18 Duncan DB. Multiple comparison methods for comparing regression coefficients. Biometrics 1970; 26: 141-3.

19 Glantz SA. Biostatistics: how to detect, correct and prevent errors in the medical literature. Circulation 1980; 61:
$1-7$.

20 O'Brien PC, Shampo MA. Statistics for clinicians: 7. Regression. Mayo Clin Proc 1981; 56: 452-4.

21 Goldstein DS. Plasma norepinephrine during stress in essential hypertension. Hypertension 1981; 3: 551-6.

22 Ayman D. Heredity in arteriolar (essential) hypertension. Arch Intern Med 1934; 53: 792-802.

23 Biron P, Mongeau JG, Bertrand D. Familial aggregation of blood pressure in 558 adopted children. Can Med Assoc $\mathcal{F}$ 1976; 115: 773-4.

24 McIlhany ML, Shaffer JW, Hines EA Jr. The heritability of blood pressure: an investigation of 200 pairs of twins using the cold pressor test. Fohns Hopkins Med $\mathcal{F}$ 1975; 136: 57-64.

25 Reid WD, Laragh JH. Sodium and potassium intake, blood pressure, pressor response to angiotensin. Proc Soc Exp Biol Med 1965; 120: 26-9.

26 Rankin LI, Luft FC, Henry DP, Gibbs PS, Weinberger $M H$. Sodium intake alters the effects of norepinephrine on blood pressure. Hypertension 1981; 3: 650-6.

27 Folkow B. Cardiovascular structural adaptation; its role in the initiation and maintenance of primary hypertension. Clin Sci 1978; 55: 35-225.

28 Blaustein MP. Sodium ions, calcium ions, blood pressure regulation, and hypertension: reassessment and a hypothesis. Am f Physiol 1977; 232: C165-73.

29 Scherer B, Friedmann B, Dumbs A, Holzmann K, Weber PC. Urinary prostaglandins in human neonates: relationship to kidney function and blood pressure. Klin Wochenschr 1980; 58: 449-55.

30 Weidmann P, Keusch G, Flammer J, Ziegler WH, Reubi FC. Increased ratio between changes in blood pressure and plasma norepinephrine in essential hypertension. f Clin Endocrinol Metab 1979; 48: 727-31. 